\title{
Analysis of Mathematical Model to Prevent Increase the Number of Smokers
}

\author{
Tri Andri Hutapea, \\ Mathematics Department,FMIPA \\ Universitas Negeri Medan \\ Medan, Indonesia \\ triandrihutapea@unimed.ac.id
}

\author{
Fidelis Zai \\ Mathematics Department, FMIPA \\ Universitas Negeri Medan \\ Medan, Indonesia \\ fideliszai@gmail.com
}

\author{
Lasker P Sinaga \\ Mathematics Department,FMIPA \\ Universitas Negeri Medan \\ Medan, Indonesia \\ lazer_integral@yahoo.com
}

\begin{abstract}
This study aimed to analyze the prevention of the increase the number of smokers in a population through a mathematical model. This study construct based on some research before, which are paper has different investigation about smoking mathematics modelling and curtailing. This research discuss about controlling the increase of the number of smokers by campaign including regulations. Moreover, the population was divided into six compartments, namely potential smokers, active smokers, temporary quit smokers, former smokers, people who is promoting to stop smoking by allowing campaign, and people who is recovered smoking. It is represent by a nonlinear differential system. The theoretical analysis of mathematics model that the associated smoking equilibrium is local-asymptotically stable whenever a certain threshold, known as the smokers generation number. The model shows that the impact of awareness created by campaigns on the smoking cessation increases in, smoker population decreases. It's also shows on graphically by simulation steps which is consider initial condition.
\end{abstract}

Keywords - compartments models, smoking, campaign, stability, simulation

\section{INTRODUCTION}

A recent report reported by the World Lung Foundation (WLF) notes that deaths causes of smoking have almost tripled in one last decade. Prediction of The WLF and the American Cancer Society, one billion people will die from tobacco use in this century or one person will die every six seconds, when the trend continues. The issue also reported by www.tobaccoatlas.org, that tobacco has killed 50 million people in the past 10 years, and cigarettes are responsible for over $15 \%$ of all male deaths and $7 \%$ of female deaths. In China, tobacco has become the number one killer that causes 1.2 million deaths per year and that number is expected to increase to 3.5 million a year by 2030 . Michael Eriksen, one of the researchers and Director of Georgia State University's Institute of Public Health, revealed almost $80 \%$ of people who die tobacco-related diseases were in developing country. Meanwhile, WLF CEO Peter Baldini accused the cigarettes industry of not caring about the harmful effects that can be caused from these cigarettes.

There are policies and act to prevent the damage that causes of smoking. For instance, Indonesian government enforce regulation, PP RI No. 109 Tahun 2012 and advertisement to forbid smoking in general area, even increasing the price of cigarettes. On the other hands, there are researchers has been investigated about harmful effect and prevention of smoking, [1], [2], [4], [5], [7], [8], [14], [15], [16], and [17]. Verma and Agarwal [15], has analyzed mathematical model of smoking, that is PSQ models (P: Potential smokers, S: active smokers, Q: former smokers) and assumed the population were constant. On [14], the article developed Castilo-Garsow model's that construct the new compartments, that is $\mathrm{Q}_{\mathrm{t}}$ : temporary smokers. Researchers investigated smoking mathematical models which is consider campaign factors, also Analyzing global dynamic of smoking mathematical models included smoking ban by media has been investigated on [2] and [15]. Studying mathematical models of spread smoking has analyzed on [7]. By the fact of harmful effect of smoking and based on fifth papers, this research studies analysis of mathematical models to prevent increase the numbers of smokers by control regulation and campaign smoking ban.

\section{MATHEMATICAL MODEL}

On this study, let the number of total population on time $t$ is $N(t)$. The population divides into six compartments, that is, potential smokers $P(t)$, active smokers $S(t)$, smokers who 
temporarily quit smoking $Q_{t}(t)$, smokers who permanently quit smoking $Q_{p}(t)$, people who to promote smoking cessation controlling by campaign and regulation smoking ban $C(t)$, and people who recover smoking $R(t)$. People, who is controlled by campaign and regulation, are settled in $P(t), S(t)$, and $Q_{t}(t)$. Let $C(t)$ defined, $C(t)=P(t)+S(t)+Q_{t}(t)$.

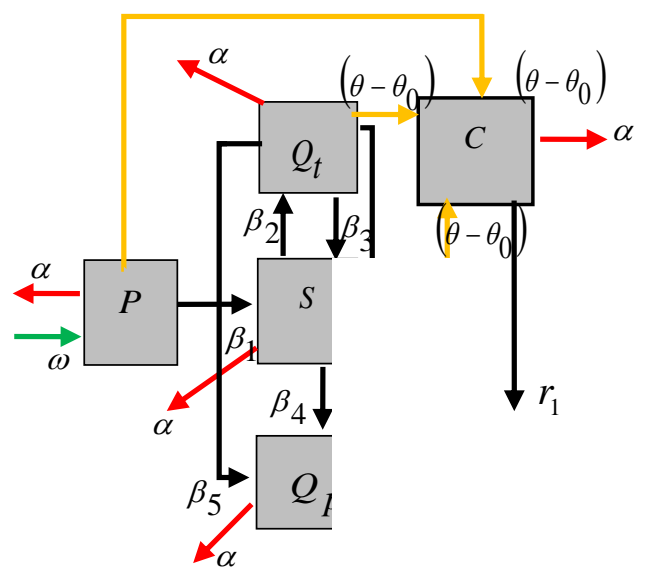

Fig 1. Construct model

Sixth compartments fluc

ked

to every compartment.

rate

$P(t)$ with $S(t) ; \beta_{2}$ : contact rate $S(t)$ with $Q_{t}(t) ; \beta_{3}$ : contact rate $Q_{t}(t)$ with $S(t) ; \beta_{4}$ : contact rate $Q_{p}(t)$ with $Q_{t}(t) ; \alpha$ : rate of natural deaths; $r_{1}$ : recovered rate of $C(t) ; r_{2}$ : recovered rate of $S(t) ; r_{3}$ : recovered rate of $Q_{t}(t) ; r_{4}$ : recovered rate of $Q_{t}(t)$, and $\left(\theta-\theta_{0}\right)$ (difference rate of implementing and fading of campaign also regulation smoking ban).

\section{RESULT AND DISCUSSION}

Based on model construction, dynamic of individual in every compartment express in nonlinear differential system, that is:

$$
\begin{aligned}
& \frac{d P}{d t}=\omega-\beta_{1} P S-\left(\left(\theta-\theta_{0}\right)+\alpha\right) P \\
& \frac{d S}{d t}=\beta_{1} P S+\beta_{3} Q_{t}-\left(\beta_{2}+\beta_{4}+\left(\theta-\theta_{0}\right)+r_{2}+\alpha\right) S \\
& \frac{d Q_{t}}{d t}=\beta_{2} S-\left(\beta_{3}+\beta_{5}+\left(\theta-\theta_{0}\right)+r_{3}+\alpha\right) Q_{t} \\
& \frac{d Q_{p}}{d t}=\beta_{5} Q_{t}+\beta_{4} S-\left(r_{4}+\alpha\right) Q_{p} \\
& \frac{d C}{d t}=\left(\theta-\theta_{0}\right) C+\theta_{0} C_{0}-\left(r_{1}+\alpha\right) C \\
& \frac{d R}{d t}=\left(r_{1} C+r_{2} S+r_{3} Q_{t}+r_{4} Q_{p}\right)-\alpha R
\end{aligned}
$$

By the system (1), $N=P+S+Q_{t}+Q_{p}+C+R$, then rate of change the number of population represented,

$$
\begin{aligned}
\frac{d N}{d t}= & \frac{d\left(P+S+Q_{t}+Q_{p}+C+R\right)}{d t} \\
& =\omega+\theta_{0} C_{0}-\alpha N .
\end{aligned}
$$

For $\frac{d N}{d t}=0$, is derived $\quad N=\frac{\omega+\theta_{0} C_{0}}{\alpha}$. It means that maximum of the number population is $\frac{\omega+\theta_{0} C_{0}}{\alpha}$. Therefore, this study defined:

$T=\left\{\begin{array}{c}\left(\begin{array}{c}* * * * * * * \\ P, S, Q_{t}, Q_{p}, C, R\end{array}\right) \in R_{6}^{+} ; \\ * \quad * \quad * \quad * \quad * \quad * \quad \omega+\theta_{0} C_{0} \\ 0<P+S+Q_{t}+Q_{p}+C+R \leq \frac{\omega}{\alpha}\end{array}\right\}$.

Furthermore, dynamic of a nonlinear system can understand by solution of the system, however the solution of a nonlinear system is difficult. The alternative ways to know the solution of a nonlinear system is studying behavior of around equilibrium points.

\section{Theorem 2.1 (Equilibrium Point)}

Given $_{R_{0}}=\frac{\beta_{2}+\beta_{4}+r_{2}+\left(\theta-\theta_{0}\right)+\alpha}{\beta_{1}}$, is the number of basic reproduction which is stated the number of smokers generation on System (1).

a) If $R_{0} \leq 1$, then System (1) have one equilibrium point, that is

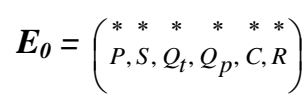




$$
=\left(\frac{\omega}{a_{1}}, 0,0,0,0,0\right), a_{1}=\left(\theta-\theta_{0}\right)+\alpha .
$$

b) If $R_{0}>1$, System (1) have one equilibrium point, that is

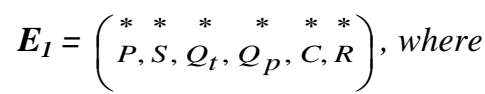

$$
P=\frac{\omega}{\beta_{1} \cdot S+a_{1}}, S=\frac{\beta_{3}+\beta_{5}+r_{3}+a_{1}}{\beta_{2}} \sqrt{\frac{\beta_{2}\left(\beta_{2}+\beta_{4}+r_{2}+a_{1}-\beta_{1} \cdot P\right)}{\beta_{3}\left(\beta_{3}+\beta_{5}+r_{3}+a_{1}\right)}}
$$$$
Q_{t}^{*}=\sqrt{\frac{\beta_{2}\left(\beta_{2}+\beta_{4}+r_{2}+a_{1}-\beta_{1} \cdot P\right)}{\beta_{3}\left(\beta_{3}+\beta_{5}+r_{3}+a_{1}\right)}},
$$$$
Q_{p}^{*}=\frac{\beta_{5}\left(Q_{t}^{*}+S\right)}{r_{4}+\alpha}, \quad C=\frac{\theta_{0} C_{0}}{\left(r_{1}+\alpha\right)-\left(\theta-\theta_{0}\right)}, \text { and }
$$

$$
R=\frac{r_{1} C+r_{2} S+r_{3} Q_{t}^{*}+r_{4} Q_{p}^{*}}{\alpha} .
$$

Furthermore, $\boldsymbol{E}_{\boldsymbol{0}}$ is equilibrium point not endemic smokers and $\boldsymbol{E}_{\boldsymbol{I}}$ is equilibrium endemic smokers. Moreover, research are going to analyze stability of $\boldsymbol{E}_{\boldsymbol{l}}$. Analyzing stability $\boldsymbol{E}_{\boldsymbol{l}}$ is learned by Jacobian matrix of System (1). Eigen value of the matrices determine stability of the equilibrium point $\boldsymbol{E}_{\boldsymbol{l}}$.

By linearizing the System (1) about endemic equilibrium $\mathbf{E}_{\mathbf{1}}$ we get the Jacobian matrix:

$$
J\left(\boldsymbol{E}_{1}\right)=\left[\begin{array}{llllll}
\frac{\partial f_{1}}{d P} & \frac{\partial f_{1}}{d S} & \frac{\partial f_{1}}{d Q_{t}} & \frac{\partial f_{1}}{d Q_{p}} & \frac{\partial f_{1}}{d C} & \frac{\partial f_{1}}{d R} \\
\frac{\partial f_{2}}{d P} & \frac{\partial f_{2}}{d S} & \frac{\partial f_{2}}{d Q_{t}} & \frac{\partial f_{2}}{d Q_{p}} & \frac{\partial f_{2}}{d C} & \frac{\partial f_{2}}{d R} \\
\frac{\partial f_{3}}{d P} & \frac{\partial f_{3}}{d S} & \frac{\partial f_{3}}{d Q_{t}} & \frac{\partial f_{3}}{d Q_{p}} & \frac{\partial f_{3}}{d C} & \frac{\partial f_{3}}{d R} \\
\frac{\partial f_{4}}{d P} & \frac{\partial f_{4}}{d S} & \frac{\partial f_{4}}{d Q_{t}} & \frac{\partial f_{4}}{d Q_{p}} & \frac{\partial f_{4}}{d C} & \frac{\partial f_{4}}{d R} \\
\frac{\partial f_{5}}{d P} & \frac{\partial f_{5}}{d S} & \frac{\partial f_{5}}{d Q_{t}} & \frac{\partial f_{5}}{d Q_{p}} & \frac{\partial f_{5}}{d C} & \frac{\partial f_{5}}{d R} \\
\frac{\partial f_{6}}{d P} & \frac{\partial f_{6}}{d S} & \frac{\partial f_{6}}{d Q_{t}} & \frac{\partial f_{6}}{d Q_{p}} & \frac{\partial f_{6}}{d C} & \frac{\partial f_{6}}{d R}
\end{array}\right]
$$

$$
=\left|\begin{array}{cccccc}
-k_{1} & -\beta_{1} & 0 & 0 & 0 & 0 \\
\beta_{1} & -k_{2} & \beta_{3} & 0 & 0 & 0 \\
0 & \beta_{2} & -k_{3} & 0 & 0 & 0 \\
0 & \beta_{4} & \beta_{5} & -\left(r_{4}+\alpha\right) & 0 & 0 \\
\left(\theta-\theta_{0}\right) & \left(\theta-\theta_{0}\right) & \left(\theta-\theta_{0}\right) & 0 & -\left(r_{1}+\alpha\right) & 0 \\
0 & r_{2} & r_{3} & r_{4} & r_{1} & -\alpha
\end{array}\right|
$$

Where, $k_{1}=\beta_{1} \cdot{ }^{*}+a_{1}, k_{2}=\left[\beta_{1}-\left(\beta_{2}+\beta_{4}+r_{2}+a_{1}\right)\right], \quad$ and $k_{3}=\left(\beta_{3}+\beta_{5}+r_{3}+a_{1}\right)$.

Theorem 2.2 (Local Stability)

Given $R_{0}=\frac{\beta_{2}+\beta_{4}+r_{2}+a_{1}}{\beta_{1}}$, and endemic equilibrium point of System (1) $\boldsymbol{E}_{\boldsymbol{I}}$ that is (2). If $R_{0}>1$, then equilibrium point $\boldsymbol{E}_{\boldsymbol{l}}$ is local stability asymptotic.

\section{Proof:}

By linearizing the System (1), now we have analyzed the stability of equilibrium point $\boldsymbol{E}_{\boldsymbol{l}}$, and for this we calculate the characteristic equation of $J\left(\boldsymbol{E}_{1}\right)=\operatorname{det}\left(\lambda I-J\left(E_{1}\right)\right)=0$. By this equation, based on Routh-Hurwitz also Theorem Olsder (1994), we derived all eigen value are negative.

Next, we are going to simulate the behavior of the models for prevention the increase the number of smokers.

We already have, the domain of System (1),

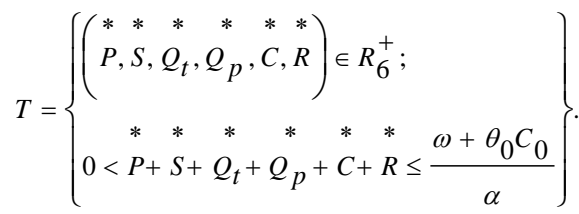

It's clearly, that we need initial conditions, to clarify the dynamic of System (1). Previously, it is important to classify parameter that caused of individual of $P(t)$ become $S(t)$, that is $\beta_{1}$ (contact rate $P(t)$ with $\left.S(t)\right), \beta_{2}$ (contact rate $S(t)$ with $\left.Q_{t}(t)\right), \quad \beta_{3}\left(\right.$ contact rate $Q_{t}(t)$ with $\left.S(t)\right), \beta_{4}$ (contact rate $Q_{p}(t)$ with $\left.Q_{t}(t)\right),\left(\theta-\theta_{0}\right)$ (difference rate of implementing and fading of campaign also regulation smoking ban) and 
$r_{1}$ (recovered rate of $C(t)$ ), without ignore $\alpha$ (rate of natural deaths)

Fig.2, show dynamic of System (1), $\beta_{1}>\left(\theta-\theta_{0}\right)$, then $P(t) \rightarrow 0$, whereas $t \rightarrow \infty$.

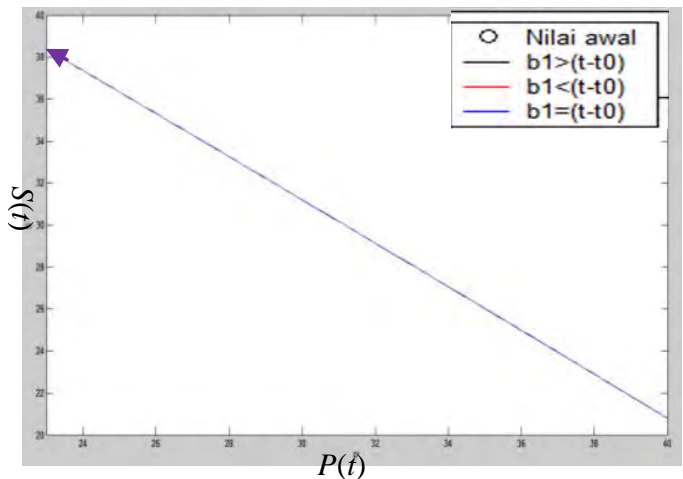

Fig 2. Projection of $P(t)$ becomes $S(t)$,

for $t \rightarrow \infty$

g.3 describes that dynamics of increase smokers is caused $\beta_{1}, \beta_{2}$, and $\beta_{3}$. If $\beta_{1}>\left(\beta_{2}-\beta_{3}\right)$, then rate of individual on $P(t)$ to $S(t)$ is rapid relatively.

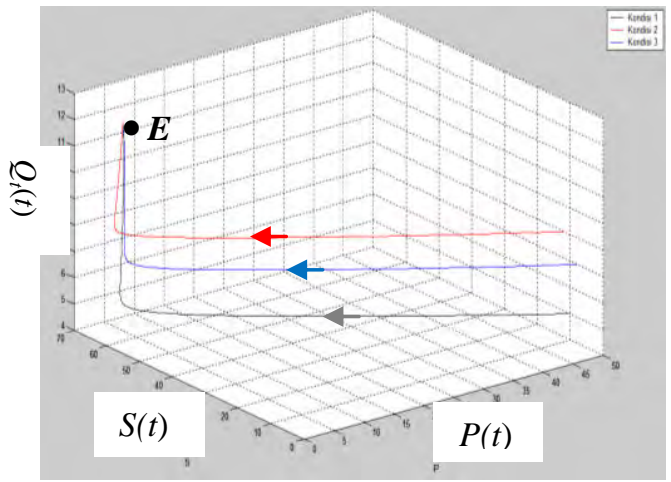

Fig 3. Dynamics of increasing smokers caused of $\beta_{1}$ and $\beta_{2}$, for $t \rightarrow \infty$.

Fig.4 describes that displacement the number of smokers active influences by comparing $\left(\beta_{2}-\beta_{3}\right)$ and $\left(\theta-\theta_{0}\right)$. Based on simulation, for $\left(\beta_{2}-\beta_{3}\right)<\left(\theta-\theta_{0}\right)$, so the smokers goes to campaign compartment.

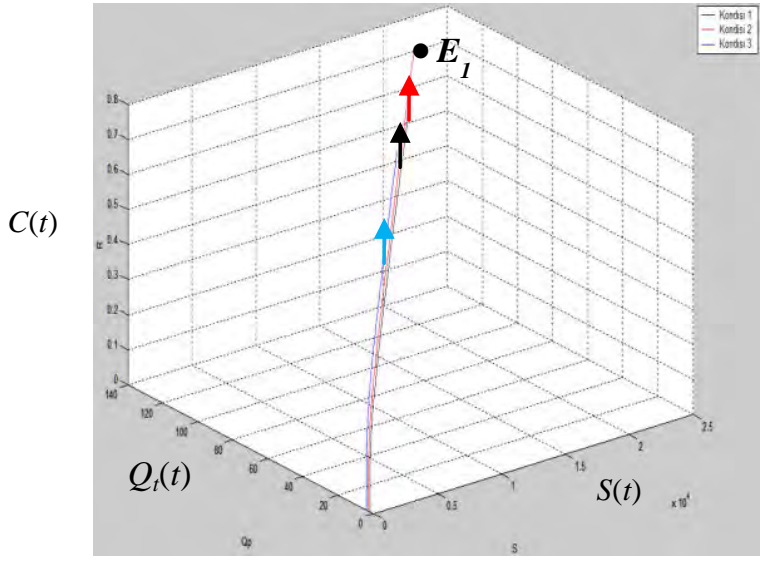

Fig 4. Dynamics of Increase the number of Smokers that influenced by $\left(\beta_{2}-\beta_{3}\right)$ and $\left(\theta-\theta_{0}\right)$, for $t \rightarrow \infty$.

\section{CONCLUSION}

The first conclusion on this research is mathematical model of increase of the number of smokers, which is expressed in a differential nonlinear system in sixth dimension. The second, Based on the model, we got two equilibrium point, that is, $\boldsymbol{E}_{\boldsymbol{0}}$ and $\boldsymbol{E}_{\boldsymbol{l}}$. The third, factors are influenced the increase of the number of smokers, that is, rate of contact potential smokers with active smokers, rate of contact individual smokers with smokers who quit temporarily, rate of contact individual smokers whose quit permanently, and difference rate of implementing and fading of campaign also regulation smoking ban.

Furthermore, this research could be continued to analysis global stability of equilibrium point of System (1).

\section{ACKNOWLEDGMENT}

This research support by research institutions of Universitas Negeri Medan. We thank to dead of FMIPA Unimed, Ibu Martina Restuati and all parties which promote this research.

\section{REFERENCES}

[1] Carlos Castilo-Garsow, Guarionex Jordan-Silva, and Ariel RodriguezHerrera, "Mathematical Models For The Dynamics Of Tobacco Use, Recovery and Relapse," NewYork Publishing, American Journal Of Public Health, Volume 84)4), page 543-547, January 1997. 
[2] Hielke Buddelmeyer, and Roger Wikins, "The Effects Of Smoking Ban Regulations On Individual Smoking Rates," IZA Discussion Paper, Bonn, Germany, No.1737, September 2005.

[3] James, B., dan Boyce, W. E., Differential Equations, 2nd Edition, John Wiley and Sons Inc, United States of America, 2010, page 45-75.

[4] John C.Lang, Daniel M. Abrams, and Hans De Sterck, "The Influence Of Societal Individualism On A Century Of Tobacco Use: Modelling The Prevalance Of Smoking," Journal Math DS, Vol.2, page 135-143, July 2014.

[5] Joshua Daniel G. Banocnoc, Joleen Gail M. Fernandez, Jose Tristan Reyes, "Stability Analysis Of A Modified Smoking Model," DLSU Research Congress, De La Salle University, Manila Philippines, 2017.

[6] Kocak,H.,dan Hole, Dynamics And Bifurcation, Springer-Verlag, Newyork, 1992, page 88-103.

[7] Obaid J.A, Anwar Zeb, Gul Zaman, Shaher Momani, I.H. Jung, "Mathematical Study Of Smoking Model by Incorporating Campaign Class," Wulfenia Journal, Volume 22, December 2015.

[8] O.Sharomi and A.B. Gumel, "Curtailing Smoking Dynamics: A Mathematical Modeling Approach," Elsevier, Science Direct, Applied Mathematics and Computation Vol.195, Page 475-499, 2008.

[9] Peraturan Menteri Kesehatan RI Nomor 28 Tahun 2013 Tentang Pencantuman Peringatan Kesehatan dan Informasi Kesehatan pada Kemasan Produk, Tembakau.

[10] Peraturan Pemerintah Republik Indonesia Nomor 109 Tahun 2012 Tentang Pengamanan Bahan Yang Mengandung Zat Adiktif Berupa Produk, Tembakau Bagi Kesehatan.

[13] Perko, L., Differential Equation and Dynamical System, third Edition, pringer-Verlag, Newyork, 2001, page 97-116.

[14] Roman Ullah at al., "Dynamical Features Of A Mathematical Model On Smoking," Journal Appl. Environ. Biol. Sci,, Volume 6(1), page 9296,ISSN: 2090 - 4274, March 2016.

[15] Verma V and Agarwal M, "Global Dynamics Of a Mathematical Model On Smoking with Media Campaigns" Research Article Volume 4(1), page 500-512, ISSN 2319-7315, 2015.

[16] Zainab Alkhudhari, Sarah Al-Sheikh, Salma Al-Tuwairqi, "Global Dynamics Of A Mathematical Model On Smoking," Hindawi Publishing Corporation ISRN Applied Mathematics, Vol 1, Article ID 847075, 2014.

[17] Zainab Alkhudhari, Sarah Al-Sheikh, Salma Al-Tuwairqi, "The Effects Of Heavy Smokers On The Dynamics Of Smoking Model", International Journal Of Differential equations And Applications, Vol. 14 No.4, Page 343-356, 2015. 